\title{
Targeted Alpha-Particle Immunotherapy with Bismuth-213 and Actinium-225 for Acute Myeloid Leukemia
}

\author{
Joseph G Jurcic
}

\begin{abstract}
Lintuzumab, a humanized anti-CD33 antibody, targets myeloid leukemia cells and has modest activity against acute myeloid leukemia (AML). To increase the antibody's potency yet avoid nonspecific cytotoxicity seen with $\beta$-emitting isotopes, lintuzumab was conjugated to the $\alpha$-emitters bismuth-213 $\left({ }^{213} \mathrm{Bi}\right)$ and actinium-225 $\left({ }^{225} \mathrm{Ac}\right)$. The 46 -minute half-life of ${ }^{213} \mathrm{Bi}$ limits its widespread use. Therefore, ${ }^{225} \mathrm{Ac}$ was also conjugated to various antibodies using DOTA-SCN. We conducted a phase I trial of ${ }^{213} \mathrm{Bi}$-lintuzumab and subsequently administered cytarabine with ${ }^{213} \mathrm{Bi}$-lintuzumab in a phase I/II study. The toxicity and biological activity of ${ }^{225} \mathrm{Ac}$-linutuzumab in patients with relapsed/refractory $A M L$ in a phase I dose-escalation trial was determined. An initial phase I trial demonstrated the feasibility, safety and antileukemic activity of ${ }^{213} \mathrm{Bi}$-lintuzumab. ${ }^{213} \mathrm{~B}$ i-lintuzumab produced responses in $24 \%$ of $A M L$ patients receiving doses $\geq 37 \mathrm{MBq} / \mathrm{kg}$ after partial cytoreduction with cytarabine. ${ }^{225} \mathrm{Ac}$-labeled immunoconjugates killed in vitro at doses at least 1,000 times lower than ${ }^{213} \mathrm{Bi}$ analogs. Eighteen patients with relapsed/refractory $\mathrm{AML}$ received 18.5 to $148 \mathrm{kBq} / \mathrm{kg}$ of ${ }^{225} \mathrm{Ac}$-lintuzumab in a phase I study. Dose-limiting toxicities were myelosuppression lasting $>35$ days in one patient and death due to sepsis in two patients. The maximum tolerated dose (MTD) was $111 \mathrm{KBg} / \mathrm{kg}$. Bone marrow blast reductions were seen across all dose levels. Targeted $\alpha$ particle immunotherapy with ${ }^{213} \mathrm{Bi}$ - and ${ }^{225} \mathrm{Ac}$-lintuzumab is safe, has significant antileukemic effects, and can produce remissions after partial cytoreduction.
\end{abstract}

Keywords: Alpha particle, Immunotherapy, Acute myeloid leukemia.

How to cite this article: J urcic J G. Targeted Alpha-P article Immunotherapy with Bismuth-213 and Actinium-225 for Acute Myeloid Leukemia. J Postgrad Med Edu Res 2013;47(1): 14-17.

\section{Source of support Nil}

Conflict of interest: None declared

\section{INTRODUCTION}

Although standard induction therapy with cytarabine and an anthracycline produces complete remissions (CR) in 50 to $70 \%$ of patients with acute myeloid leukemia $(A M L)$, but long-term survival is seen in only 20 to $40 \%$ of patients. ${ }^{1}$ Following relapse, salvage chemotherapy produces remissions in only 20 to $25 \%$ of patients. While allogeneic hematopoietic cell transplantation (HCT) can result in longterm survival in approximately $30 \%$ of patients with relapsed $A M L$, most patients are not appropriate candidates due to age, comorbidities or lack of a suitable donor. ${ }^{2}$ The prognosis for elderly patients is even worse with a 5 -year survival rate of $5 \%$ for patients more than 65 years of age. ${ }^{3}$
Therefore, new therapies are needed to improve survival and reduce therapy-related toxicity.

Early studies showed that anti-CD 33 constructs containing $\beta$ particle-emitting iodine-131 or yttrium-90 could eliminate large leukemic burdens but resulted in prolonged myelosuppression requiring $\mathrm{HCT}, 4,5$ The unique physical and radiobiological properties of $\alpha$-particles may provide more efficient tumor cell killing and reduce the nonspecific cytotoxic effects seen with $\beta$-emitters. The $\alpha$-particles have a shorter range $(50-80 \mu \mathrm{m}$ compared to $800-10,000 \mu \mathrm{m}$ of $\beta$-particles) and a higher linear energy transfer (LET) (100 keV/ $\mu \mathrm{m}$ compared to $0.2 \mathrm{keV} / \mu \mathrm{m}$ of $\beta$-particles). ${ }^{6}$ As few as one or two $\alpha$-particles can kill a target cell. Therefore, the potential for more efficient and specific antitumor effects with less damage to surrounding normal tissues makes $\alpha$-particle immunotherapy an attractive approach for the treatment of cytoreduced or minimal disease.

Lintuzumab (HuM 195) is a humanized monoclonal antibody that targets CD 33, a $67-\mathrm{kD}$ a cell surface glycoprotein expressed on most myeloid leukemia cells. It is also found on committed myelomonocytic and erythroid progenitors but not on pluripotent stem cells, granulocytes or nonhematopoietic tissues. ${ }^{7,8}$ Lintuzumab induces antibody-dependent cell-mediated cytotoxicity and can fix human complement invitro. ${ }^{9}$ Previous studies demonstrated that lintuzumab can target leukemia cells in patients without immunogenicity, ${ }^{10}$ eliminate minimal residual disease in acute promyelocytic leukemia, ${ }^{11}$ and produce occasional remissions in $A M L{ }^{12-14}$ To increase the potency of the antibody but avoid the nonspecific cytotoxicity seen with the $\beta$-emitters like iodine-131 (131 I) and yttrium-90 (90 Y), we conjugated lintuzumab to bismuth-213 $\left({ }^{213} \mathrm{Bi}\right)$ and actinium-225 $\left({ }^{225} \mathrm{Ac}\right)$, the $\alpha$-emitters.

\section{Alpha-Particle Immunotherapy with ${ }^{213} \mathrm{Bi}$-Lintuzumab Preclinical Studies}

${ }^{213} \mathrm{Bi} \mathrm{(} \mathrm{t} 1 / 2=45.6$ minutes) is a radiometal that emits $\alpha$-particle with $8 \mathrm{M} \mathrm{eV}$ energy. Additionally, a $440 \mathrm{keV}$ photon emission accompanies $26.5 \%$ of ${ }^{213} \mathrm{Bi}$ decays, allowing detailed biodistribution and dosimetry studies to be performed. B ismuth-labeled lintuzumab in vitro resulted in dose- and specific activity-dependent killing of $\mathrm{CD} 33^{+}$ HL 60 cells. A pproximately $50 \%$ of target cells were killed 
when only two bismuth atoms were bound to the cell surface. $^{16}$

\section{Single-Agent Phase I Trial}

In our previous work, based on these preclinical data, 18 patients with relapsed and refractory A M L (17 patients) or chronic myelomonocytic leukemia (one patient) were treated with ${ }^{213} \mathrm{Bi}$-lintuzumab. ${ }^{17}$ The drug was given as a 5-minute infusion, two to four times daily in 148 to $925 \mathrm{M} \mathrm{Bq}$ fractions over 2 to 4 days. B ecause ${ }^{213} \mathrm{Bi}$ yields were limited by the activity of each ${ }^{225} \mathrm{~A} \mathrm{C/}{ }^{213} \mathrm{Bi}$ generator and because of constraints on the specific activity that could be achieved for any one injection, we escalated radioactivity doses by increasing the number of injections. Patients received a total of 3 to 7 injections. Five dose levels were studied: 10.36, 15.54, 20.72, 25.9 and $37 \mathrm{M} \mathrm{Bq} / \mathrm{kg}$. Biodistribution and dosimetry studies were performed by obtaining $\gamma$ camera images after the first and last dose of ${ }^{213} \mathrm{~B} \mathrm{i}$-lintuzumab. U sing a $20 \%$ photopeak window centered at $440 \mathrm{keV}$, thirty, 1-minute images beginning at the start of each injection followed by ten, 3-minute images were collected. ${ }^{18}$

No significant extramedullary toxicities were seen. Grade I and II liver function abnormalities were seen in four patients (22\%). The onset was typically 5 to 14 days following treatment, and these abnormalities resolved within 3 to 14 days. All 17 evaluable patients developed myelosuppression with a median time to recovery of 22 days (range: $12-41$ days). Nearly all the ${ }^{213} \mathrm{Bi}$-lintuzumab rapidly localized to and was retained in areas of leukemic involvement, including the bone marrow, liver and spleen. Despite avidity for free bismuth, the kidneys were not visualized. There was no significant catabolism or clearance of the drug, confirming the stability of the construct. The mean absorbed dose per amount of injected activity to the marrow, and therefore to $\mathrm{CD} 33^{+}$target cells, was $9.8 \mathrm{mSv} /$ $\mathrm{MBq}$ (range: $2.6-29.4 \mathrm{mSv} / \mathrm{MBq}$ ). A bsorbed dose ratios between these sites and the whole body were 1,000-fold greater than those seen with $\beta$-emitting constructs in this antigen system and patient population. Blood and plasma antibody concentrations displayed typical $\alpha$ distributions over the first 20 to 40 minutes, followed by slower $\beta$ clearance over the remaining 3 hours of sample collection. ${ }^{17}$

Fourteen (93\%) of 15 evaluable patients had reductions in circulating blasts, and $14(78 \%)$ of 18 patients had reductions in the percentage of bone marrow blasts (Fig. 1). No patients achieved CR, likely due to large tumor burdens in heavily pretreated patients and to the relatively low specific activities (329-766 M B q/mg) of ${ }^{213} \mathrm{Bi}$-lintuzumab. $\mathrm{N}$ evertheless, this study demonstrated the saf ety, feasibility

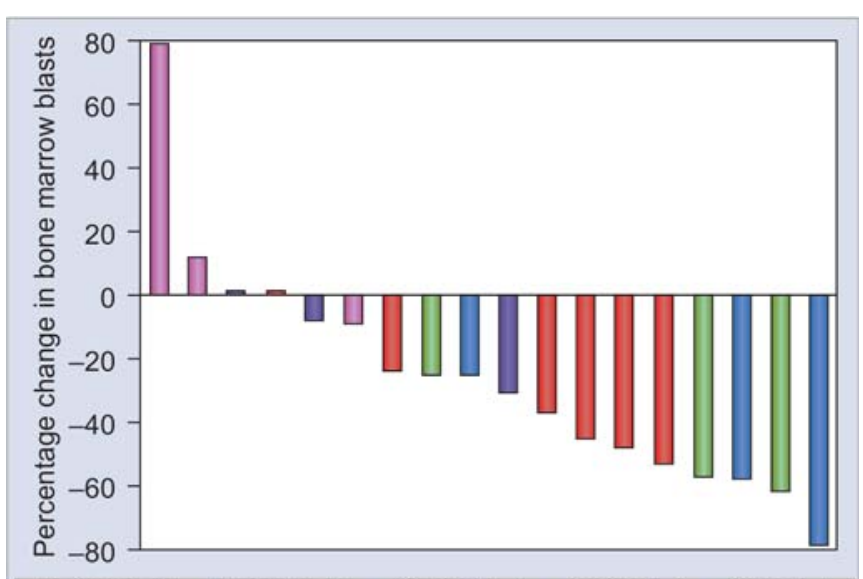

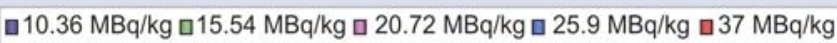

Fig. 1: Percentage change in bone marrow blasts after treatment with ${ }^{213} \mathrm{Bi}$-lintuzumab in 18 patients in a phase I trial

and antileukemic effects of ${ }^{213} \mathrm{Bi}$-lintuzumab and was the first proof-of-concept for systemic targeted $\alpha$-particle immunotherapy in humans. ${ }^{17}$

\section{Sequential Cytarabine and ${ }^{213} \mathrm{Bi}$-Lintuzumab}

It may be hypothesized that a 1-2 log reduction in tumor burden could increase the number of ${ }^{213} \mathrm{Bi}$ atoms delivered to leukemia cells and produce remissions. To determine the effects of ${ }^{213} \mathrm{~B} \mathrm{i}$-lintuzumab against cytoreduced disease, the authors conducted a phase I/II trial in which patients first received a nonremittive dose of cytarabine to decrease the leukemic burden. ${ }^{19}$ Thirty-one patients with newly diagnosed $(n=13)$ or relapsed/refractory $(n=18) \mathrm{AML}$ were treated. Patients received cytarabine at a dose of 200 $\mathrm{mg} / \mathrm{m}^{2}$ daily by intravenous continuous infusion for 5 days. Within 8 days after completion of cytarabine, 2 to 4 injections of ${ }^{213} \mathrm{~B} \mathrm{i}$-lintuzumab (518-1, $262 \mathrm{M} \mathrm{B} \mathrm{q} \mathrm{each)} \mathrm{were}$ given over 1 to 2 days. Four dose levels of ${ }^{213} \mathrm{~B}$-lintuzumab were administered in the phase I portion of the trial: 18.5, $27.75,37$ and $46.25 \mathrm{M} \mathrm{B} \mathrm{q} / \mathrm{kg}$. A $\mathrm{n}$ additional 16 patients were treated at the maximum tolerated dose (M TD) in the phase II portion of the trial.

During the phase I portion, dose-limiting myelosuppression (defined as grade IV leukopenia lasting $\geq 35$ days) was seen in two of four patients treated with 46.25 $\mathrm{MBq} / \mathrm{kg}$. The MTD of ${ }^{213} \mathrm{Bi}$-lintuzumab following cytarabine was found to be $37 \mathrm{M} \mathrm{Bq} / \mathrm{kg}$. Extramedullary toxicities were mainly limited to grade I and II events, including infusion-related reactions in nine patients (29\%). Transient grade III/IV liver function abnormalities were seen in five patients (16\%). No patient had evidence of sinusoidal obstructive syndrome. Treatment-related deaths occurred in two of 21 patients (10\%) who received the M TD. ${ }^{19}$ 


\begin{tabular}{lcccccc}
\multicolumn{7}{c}{ Table 1: Results by disease status for sequential cytarabine ${ }^{213}$ Bi-lintuzumab } \\
\hline Disease status & No. of patients & CR & CRp & PR & Overall response \\
\hline Untreated AML, untreated relapse & 18 & 2 & 2 & 2 & $6(33 \%)$ \\
Primary refractory, refractory relapse & 7 & 0 & 0 & 0 & 0 \\
\hline
\end{tabular}

Significant reductions in marrow blasts were seen across all dose levels. Clinical responses were observed in six of the 25 patients (24\%; 95\% Cl: 11-44) who received doses of $\geq 37 \mathrm{M} \mathrm{Bq} / \mathrm{kg}$ [2 CR, $2 \mathrm{CR}$ with incomplete platelet recovery (CRp), and 2 PR ] (Table 1 ). All responders had poor-risk features, including age $\geq 70$ years or secondary $A M L$; however, none of the six patients receiving less than $37 \mathrm{M} \mathrm{Bq}$ had a clinical response. N one of the seven patients either with primary refractory $A M L$ or multiple treated relapsed disease responded, indicating that effective cytoreduction was necessary to achieve remission after administration of ${ }^{213} \mathrm{Bi}$-lintuzumab. The median response duration was 6 months (range: 2-12) with the median survival of 13.7 months (range: 5-30 months) among responders. ${ }^{19}$

Four patients (one at each dose level) underw ent detailed biodistribution and pharmacokinetic studies. In contrast to the results seen in the initial phase I trial where ${ }^{213} \mathrm{~B}$ lintuzumab was given as a single agent, ${ }^{15}$ cardiac blood pooling was seen after the last injection in one patient treated with $27.5 \mathrm{M} \mathrm{Bq} / \mathrm{kg}$, indicating saturation of CD 33 antigen sites within the bone marrow, liver and spleen. M oreover, reduced bone marrow uptake of ${ }^{213} \mathrm{~B} \mathrm{i}$-lintuzumab was seen after multiple injections in all four patients, indicating saturation of antigen sites after partial cytoreduction with cytarabine. Although a relatively small group of heterogeneous patients were included in this trial, it showed that targeted $\alpha$-particle immunotherapy can be effective at reducing low-volume disease.

\section{Actinium-225-Lintuzumab: A Targeted Alpha-Particle Nanogenerator}

\section{Preclinical Studies}

The major obstacles to the widespread use of ${ }^{213} \mathrm{Bi}$ are its short half-life and the requirement of an on-site ${ }^{225} \mathrm{Acl}{ }^{213}$ $\mathrm{Bi}$-generator. Therefore, the author developed a second generation construct in which the isotope generator is directly conjugated to a tumor-specific antibody. In this strategy, ${ }^{225} \mathrm{Ac}\left(\mathrm{t}^{\mathrm{1}} \frac{1}{2}=10\right.$ days) can serve as an in vivo generator of four $\alpha$-particles at or within a cancer cell. The macrocyclic ligand 1,4,7,10-tetraazacyclododecane tetraacetic acid (DOTA) and its derivatives have been used for labeling of antibodies with ${ }^{225} \mathrm{~A}$ c. A two-step procedure was devel oped in which ${ }^{225} \mathrm{Ac}$ is first conjugated to DOTA -
SCN followed by labeling of this construct to antibody. ${ }^{20}$ ${ }^{225} \mathrm{~A}$ c-labeled tumor-specific antibodies can kill multiple cell lines in vitro with $L D_{50}$ values 1,000 to 10,000 times less than those of analogous ${ }^{213} \mathrm{Bi}$ constructs. These findings led to in vivo studies in nude mice bearing human prostate carcinoma and lymphoma xenografts. Single nanocurie doses of ${ }^{225} \mathrm{Ac}$-labeled tumor-specific antibodies significantly improved survival over controls and cured a substantial fraction of animals. ${ }^{21}$

\section{Phase I Study of ${ }^{225} \mathrm{Ac}$-Lintuzumab}

Based on the activity of ${ }^{225} \mathrm{Ac}$-containing radioimmunoconjugates in the animal models, we conducted a phase I trial of ${ }^{225} \mathrm{Ac}$-lintuzumab in advanced AM L. ${ }^{22}$ Eighteen patients with relapsed $(n=11)$ or refractory $(n=7) A M L$ were treated with a single infusion of ${ }^{225} \mathrm{Ac}$-lintuzumab at doses of $18.5(n=3), 37(n=4), 74(n=3), 111(n=6)$ or $148(n=2) \mathrm{kBq} / \mathrm{kg}$. Dose-limiting toxicities including myelosuppression lasting more than 35 days in one patient receiving $148 \mathrm{kB} \mathrm{q} / \mathrm{kg}$ and death from sepsis in two patients receiving 111 and $148 \mathrm{kBq} / \mathrm{kg}$ occurred. The MTD was determined to be $111 \mathrm{kBq} / \mathrm{kg}$. As expected myelosuppression was the most common toxicity. M edian time to resolution of grade IV leukopenia was 27 days (range: 0 71 days). Significant extramedullary toxicities were limited to transient grade III liver function abnormalities in three patients. We analyzed plasma pharmacokinetics by gamma counting at energy windows for two daughters of ${ }^{225} \mathrm{AC}$, francium-221 $\left({ }^{221} \mathrm{Fr}\right)$ and ${ }^{213} \mathrm{Bi}$. Two-phase elimination kinetics was seen with mean plasma $t^{1} / 2-\alpha$ and $t^{1} / 2-\beta$ of 1.9 and 38 hours, respectively, similar to other lintuzumab constructs containing long-lived radionuclides. This is in contrast to ${ }^{213} \mathrm{Bi}$-lintuzumab, where the half-life is determined primarily by the short-lived radionuclide. Peripheral blasts were eliminated in 10 of 16 evaluable patients $(63 \%)$, but only at doses of $\geq 37 \mathrm{kBq} / \mathrm{kg}$. Bone marrow blast reductions were seen in 10 of 15 evaluable patients $(67 \%)$ at 4 weeks, including eight patients (53\%) who had blast reductions of more than $50 \%$. Three patients receiving 37, 111 and $148 \mathrm{kBq} / \mathrm{kg}$ respectively achieved marrow blasts of $5 \%$ or less.

\section{SUMMARY}

Systemically administered targeted $\alpha$-particle immunotherapy is feasible and has significant antitumor activity. 
Targeted Alpha-Particle Immunotherapy with Bismuth-213 and Actinium-225 for Acute Myeloid Leukemia

The shorter range and higher linear energy transfer of $\alpha$-particles compared with $\beta$-particles may allow for more efficient and selective killing of individual tumor cells. These physical properties suggest that radioimmunotherapy with $\alpha$-emitters may be best suited for the treatment of smallvolume disease, as borne out in these clinical trials. A lthough reductions in leukemic blasts were seen when both ${ }^{213} \mathrm{~B}$ and ${ }^{225} \mathrm{Ac-lintuzmab}$ were given as single agents in phase I trials, remissions were only seen after effective cytoreduction. The use of ${ }^{225} \mathrm{Ac}$ can overcome the logistical difficulties associated with short-lived radionuclides such as ${ }^{213} \mathrm{Bi}$. B uilding on the encouraging results seen with ${ }^{213} \mathrm{Bi}$ lintuzumab for cytoreduced leukemia, we are now conducting a multicenter phase I/II trial of ${ }^{225} \mathrm{Ac}$-lintuzumab in combination with low-dose cytarabine for el derly patients with untreated $\mathrm{AML}$. These studies provide the rationale for further investigation of targeted $\alpha$-particle immunotherapy for minimal residual disease or smallvolume disease in a variety of malignancies.

\section{REFERENCES}

1. Cassileth PA, Harrington DP, A ppelbaum FR, Lazarus HM, Rowe JM, Paietta $E$, et al. Chemotherapy compared with autologous or allogeneic bone marrow transplantation in the management of acute myeloid leukemia in first remission. $\mathrm{N}$ Engl J M ed 1998;339:1649-56.

2. Stockerl-Goldstein KE, Blume KG. Allogeneic hematopoietic cell transplantation for adult patients with acute myeloid leukemia. In: Thomas ED, Blume KG, Forman SJ (Eds). Hematopoietic cell transplantation. Oxford: B lackwell Science, Inc 1999;823-34.

3. Howlader $N$, N oone AM, K rapcho $M$, N eyman $N$, A minou $R$, Altekruse SF, et al. SEER Cancer Statistics Review, 1975-2009 (V intage 2009 Populations), N ational Cancer Institute. B ethesda, MD, http://seer.cancer.gov/csr/1975_2009_pops09/, based on November 2011 SEER data submission, posted to the SEER web site, A pril 2012.

4. Burke J M, Caron PC, Papadopoulos EB , Divgi CR, Sgouros G, Panageas KS, et al. Cytoreduction with iodine-131-anti-CD 33 antibodies before bone marrow transplantation for advanced myel oid leukemias. B one M arrow Transplant 2003;32:549-56.

5. Jurcic JG, Divgi $C R, M C D$ evitt $M R, M$ a D, Sgouros G, Finn $R D$, et al. Potential for myeloablation with yttrium-90-H uM 195 (anti-CD33) in myeloid leukemia. Proc Am Soc Clin Oncol 2000; 19:8a (abstr 24).

6. M cDevitt M R, Sgouros G, Finn RD, Humm JL, Jurcic JG, Larson SM, et al. Radioimmunotherapy with alpha-emitting nuclides. Eur J N ucl M ed 1998;25:1237-47.

7. AndrewsRG, Torok-Storb B, B ernstein ID. M yeloid-associated differentiation antigens on stem cells and their progeny identified by monoclonal antibodies. Blood 1983;62:124-32.

8. Griffin JD, Linch D, Sabbath K, L arcom P, Schlossman SF. A monoclonal antibody reactive with normal and leukemic human myeloid progenitor cells. Leuk Res 1984;8:521-34.

9. Caron PC, Co MS, Bull MK, A vdalovic NM, Queen C, Scheinberg DA. Biological and immunological features of humanized M 195 (anti-CD33) monoclonal antibodies. Cancer Res 1992;52:6761-67.

10. Caron PC, Jurcic JG, Scott AM, Finn RD, Divgi CR, Graham $M C$, et al. A phase $1 B$ trial of humanized monoclonal antibody M 195 (anti-CD33) in myeloid leukemia: Specific targeting without immunogenicity. Blood 1994;83:1760-68.

11. Jurcic JG, DeBlasio T, Dumont $L, Y$ ao TJ, Scheinberg DA. $M$ olecular remission induction with retinoic acid and anti-CD 33 monoclonal antibody H uM 195 in acute promyel ocytic leukemia. Clin Cancer Res 2000;6:372-80.

12. Caron PC, Dumont L, Scheinberg DA. Supersaturating infusional humanized anti-CD33 monoclonal antibody HuM 195 in myelogenous leukemia. Clin Cancer Res 1998;4:1421-28.

13. Feldman $E, K$ alaycio $M$, W einer $G$, Frankel $S$, Schulman $P$, Schwartzberg $L$, et al. Treatment of relapsed or refractory acute myeloid leukemia with humanized anti-CD33 monoclonal antibody HuM 195. L eukemia 2003;17:314-18.

14. Raza A, J urcic JG, Roboz GJ, M aris M, Stephenson JJ, W ood $B L$, et al. Complete remissions observed in acute myeloid leukemia following prolonged exposure to lintuzumab: A phase 1 trial. L euk Lymph 2009;50:1336-44.

15. M CD evitt M R, Finn RD, M a D, Larson SM, Scheinberg DA. Preparation of $\alpha$-emitting ${ }^{213} \mathrm{~B}$ i-label ed antibody constructs for clinical use. J Nucl Med 1999;40:1722-27.

16. Nikula TK, McDevitt MR, Finn RD, Wu C, Kozak RW, Garmestani K, et al. A I pha-emitting bismuth cyclohexylbenzyl DTPA constructs of recombinant humanized anti-CD 33 antibodies: Pharmacokinetics, bioactivity, toxicity and chemistry. J Nucl M ed 1999;40:166-76.

17. J urcic JG, Larson SM, Sgouros G, M CD evitt M R, Finn RD, Divgi $C R$, et al. Targeted alpha particle immunotherapy for myeloid leukemia. Blood 2002;100:1233-39.

18. Sgouros G, B allangrud $\AA$ M , Jurcic J G, M cDevitt M R, H umm $J L$, Erdi $Y E$, et al. Pharmacokinetics and dosimetry of an $\alpha$-particle emitter label ed antibody: ${ }^{213}$ B i-HuM 195 (anti-CD33) in patients with leukemia. J Nucl M ed 1999;40:1935-46.

19. Rosenblat TL, M CD evitt M R, M ulford DA, Pandit-Taskar N, Divgi $C R$, Panageas KS, et al. Sequential cytarabine and $\alpha$-particle immunotherapy with bismuth-213-Iintuzumab (HuM 195) for acute myeloid leukemia. Clin Cancer Res 2010;16:5303-11.

20. M cD evitt M R, Finn RD, Sgouros G, M a D, Scheinberg DA. A n ${ }^{225} \mathrm{~A} \mathrm{C/} /{ }^{213} \mathrm{~B}$ i generator system for therapeutic clinical applications: Construction and operation. Appl Rad Isotopes 1999;50:895-904.

21. M cD evitt M R, M a D, L ai LT, Simon J, B orchardt P, Frank RK, et al. Tumor therapy with targeted atomic nanogenerators. Science 2001;294:1537-40.

22. Jurcic JG, Rosenblat $T L, M$ CD evitt M R, Pandit-Taskar N, Carrasquillo JA, Chanel SM, et al. Phase I trial of the targeted al pha-particle nano-generator actinium-225 (225A C)-lintuzumab (anti-CD33; HuM 195) in acute myeloid leukemia (A M L). J Clin Oncol 2011;29:(suppl; abstr 6516).

\section{ABOUT THE AUTHOR}

\section{Joseph G Jurcic}

Professor, Department of Clinical M edicine; Director, Hematologic M alignancies, Columbia U niversity M edical Centre, 177 Fort W ashington 6-435 N ew Y ork, NY -10032, USA, e-mail: jgj2110@ columbia.edu 